\title{
The role of GPR1 signaling in mice corpus luteum
}

\author{
Ya-Li Yang1,*, Li-Rong Ren,*, Li-Feng Sun',*, Chen Huang1,3, Tian-Xia Xiao', \\ Bao-Bei Wang', Jie Chen', Brian A Zabel', Peigen Ren ${ }^{1}$ and Jian V Zhang'
}

${ }^{1}$ Research Laboratory for Reproductive Health, Shenzhen Institutes of Advanced Technology, Chinese Academy of Sciences, Shenzhen, China

2Shenzhen Key Laboratory of Birth Defects, Shenzhen Baoan Maternal and Child Health Hospital, Shenzhen, Guangdong, China

3University of Chinese Academy of Sciences, Shenzhen, China

${ }^{4}$ Laboratory of Immunology and Vascular Biology, Department of Pathology, Stanford University School of Medicine, Stanford, California, USA, and Center for Molecular Biology and Medicine, Veterans

Affairs Palo Alto Health Care System, Palo Alto, California, USA

*(Ya-Li Yang, Li-Rong Ren and Li-Feng Sun contributed equally to this work)

\author{
Correspondence \\ should be addressed \\ to Peigen Ren or \\ Jian V Zhang \\ Email \\ peigen.ren@siat.ac.cn or \\ jian.zhang@siat.ac.cn
}

\begin{abstract}
Chemerin, a chemokine, plays important roles in immune responses, inflammation, adipogenesis, and carbohydrate metabolism. Our recent research has shown that chemerin has an inhibitory effect on hormone secretion from the testis and ovary. However, whether G protein-coupled receptor 1 (GPR1), the active receptor for chemerin, regulates steroidogenesis and luteolysis in the corpus luteum is still unknown. In this study, we established a pregnant mare serum gonadotropin-human chorionic gonadotropin (PMSG-hCG) superovulation model, a prostaglandin F2 $\alpha$ (PGF2 $\alpha$ ) luteolysis model, and follicle and corpus luteum culture models to analyze the role of chemerin signaling through GPR 1 in the synthesis and secretion of gonadal hormones during follicular/luteal development and luteolysis. Our results, for the first time, show that chemerin and GPR1 are both differentially expressed in the ovary over the course of the estrous cycle, with highest levels in estrus and metestrus. GPR1 has been localized to granulosa cells, cumulus cells, and the corpus luteum by immunohistochemistry (IHC). In vitro, we found that chemerin suppresses hCG-induced progesterone production in cultured follicle and corpus luteum and that this effect is attenuated significantly by antiGPR1 MAB treatment. Furthermore, when the phosphoinositide 3-kinase (PI3K) pathway was blocked, the attenuating effect of GPR1 MAB was abrogated. Interestingly, PGF2 $\alpha$ induces luteolysis through activation of caspase-3, leading to a reduction in progesterone secretion. Treatment with GPR1 MAB blocked the PGF2 $\alpha$ effect on caspase- 3 expression and progesterone secretion. This study indicates that chemerin/GPR 1 signaling directly or indirectly regulates progesterone synthesis and secretion during the processes of follicular development, corpus luteum formation, and PGF2 $\alpha$-induced luteolysis.
\end{abstract}
Key Words
- chemerin
- GPR1
- corpus luteum
progesterone

Journal of Endocrinology (2016) 230, 55-65

\section{Introduction}

Chemerin, a recently discovered adipose cytokine, is also known as tazarotene-induced gene 2 (TIG2) and retinoic acid receptor responder protein 2 (RARRES2) (Zabel et al. 2006). Printed in Great Britain
Initially, chemerin was considered to be a chemoattractant ligand of $G$ protein-coupled receptors (GPRs), but was later found to be an adipocytokine that can regulate fat 
formation and adipocyte metabolism (Bozaoglu et al. 2007). It is secreted from white adipocytes and widely expressed in multiple tissues in the human body, not only in liver and white adipose tissue, but also in placenta, skin, adrenal gland, lung, intestine, pancreas, and ovary (Wittamer et al. 2003). The physiological functions of chemerin include regulation of blood pressure, inflammation, immune responses, differentiation of fat cells, and sugar metabolism (Fatima et al. 2014), and it plays a key role in metabolic diseases, such as obesity and diabetes (Goralski et al. 2007).

Chemerin acts through three receptors, chemokinelike receptor 1 (CMKLR1), G protein-coupled receptor 1 (GPR1), and chemokine (C-C motif) receptor like 2 (CCRL2), as an endocrine, paracrine, and autocrine signaling molecule. All three receptors are seven transmembrane domains (Bondue et al. 2011). Chemerin binding to CMKLR1 enhances leukocyte chemotaxis (Peng et al. 2015). Chemerin binding to CCRL2 does not stimulate chemotaxis, but might present chemerin to nearby CMKLR1-positive cells to promote its function and play a key role in immune responses, inflammation, and other physiological processes (Zabel et al. 2008). While no physiological function has been reported for chemerin binding to GPR1, it has been reported that GPR1 is highly expressed in murine animal brown adipose tissue, white adipose tissue, and skeletal muscle. GPR1 is mainly expressed in vascular cells in white adipose tissue (Rourke et al. 2014). In Gpr1-knockout mice fed a high-fat diet, glucose intolerance was found to be more serious than in WT mice. Furthermore, in a test of pyruvic acid tolerance, Gpr1-knockout mice were able to suppress glucosestimulated insulin level rise, causing a rise in blood sugar (Nazarko et al. 2008). These results suggest that GPR1 is an active receptor of chemerin and that it could regulate glucose homeostasis in the development of obesity.

It was recently reported that many chemokines play important roles in fertility and reproduction (Hausman \& Barb 2010). Tena-Sempere et al. (1999) found that in rat testicular tissue in vitro, leptin inhibited the ground state, and human chorionic gonadotropin (hCG)-stimulated testosterone secretion. Caminos et al. (2008) found that after adiponectin treatment, the ground state and hCGstimulated testosterone secretion by testicular tissue were suppressed. These results suggest that adipose cytokines with endocrine functions have direct and indirect regulatory effects on testosterone secretion by testicular cells. Similarly, many reports have recently focused on the role of the novel chemokine chemerin in the female reproductive system.

Previous research has shown that chemerin inhibits gonad hormone secretion from testis and ovary
(Li et al. 2014b). Studies have shown that the level of chemerin is increased in the blood and adipose tissue of patients with polycystic ovary syndrome (Tan et al. 2009). The level of chemerin in the blood of patients with preeclampsia is also increased (Duan et al. 2012). Studies have further found that chemerin is expressed in both human and rat placenta and that, in rats, the chemerin level is higher in placenta than in liver (Garces et al. 2012). Chemerin and its receptor, CMKLR1, have been reported to be expressed in human granulosa cells. Chemerin treatment can inhibit insulin-like growth factor-induced progesterone and estradiol secretion, and in rat granulosa cells, chemerin can suppress follicle-stimulating hormone (FSH)-induced progesterone and estradiol secretion (Reverchon et al. 2012). These results indicate that chemerin can suppress the secretion of gonadal hormones and may be an important factor in obesity and obesity-induced abnormal secretion of gonadal hormones.

The corpus luteum is a transient endocrine organ. During its development, the corpus luteum generates a series of steroids, which cause the corpus luteum to have very high metabolic activity and play an important role in maintaining normal reproductive function in mammals (Pate et al. 2012). At the same time, these steroids promote rapid cell growth, proliferation, differentiation, and angiogenesis (Devoto et al. 2009).

Chemerin and its receptors are expressed in human and mouse ovary and may suppress sexual hormone secretion (Wang et al. 2013), but there are no reports on the relationship between chemerin and the corpus luteum. Our study is the first report on the expression of the novel adipokine chemerin and its receptor GPR1 in mouse corpus luteum and characterization of its direct biological effects on steroidogenesis and luteolysis of the corpus luteum.

\section{Materials and methods}

\section{Animals}

Female C57BL/6 mice (25-day-old) were obtained from Guangdong Medical Laboratory Animal Center. All procedures related to animal use were approved by the Committee on the Use of Live Animals for Teaching and Research, Shenzhen Institutes of Advanced Technology, Chinese Academy of Sciences.

\section{Determination of estrous cycle stage}

For estrous cycle staging, vaginal smears were performed daily in the morning at the same time each day using

Published by Bioscientifica Ltd 
cotton swabs wetted with PBS; smears were placed on glass slides and cytology was evaluated under a microscope. Estrus was determined by the presence of cornified cells. Metestrus was scored by the presence of large round cells with an irregular border. A high density of leukocytes indicated the stage of diestrus, whereas small nucleated cells indicated proestrus (Becker et al. 2005).

\section{Superovulating corpus luteum model}

The 25-day-old immature female mice were injected i.p. with $5 \mathrm{IU}$ of pregnant mare serum gonadotropin (PMSG) (ProSpec, Ness-Ziona, Israel) to stimulate follicular development, followed by injection of $5 \mathrm{IU}$ of hCG (Sigma) $48 \mathrm{~h}$ after PMSG injection to induce ovulation.

Animals were anaesthetized before blood were collected by removal of eyeball and then killed by cervical dislocation before the ovaries samples were collected at 24 and $48 \mathrm{~h}$ after PMSG administration and 24, 48, 72, and $96 \mathrm{~h}$ after hCG administration. Serum samples were send to Beijing North Institute of Biological Technology (Beijing, China) to measure hormone level of estradiol, progesterone and testosterone. Ovaries were either put in RNAiso Plus (Takara Bio) and stored at $-80^{\circ} \mathrm{C}$ for total RNA isolation or fixed in Bouin's solution and embedded in paraffin for histological examination.

\section{Postpartum corpus luteum model}

Six- to 8-week-old females were housed with males, the occurrence of copulatory plugs was verified by visual examination at each day morning. Females on the third, fourth, and fifth postpartum day were injected s.c. with $25 \mu \mathrm{g} / 100 \mu \mathrm{L}$ PGF2 $\alpha$, control group injected s.c. with saline. Ovaries and blood samples (collected by removal of eyeball) were taken at $12 \mathrm{~h}$ after PGF2 $\alpha$ and saline injected. Serum was send to Beijing North Institute of Biological Technology to measure hormone level of estradiol, progesterone and testosterone. Ovaries were either snap frozen in RNAiso Plus and stored at $-80^{\circ} \mathrm{C}$ for RNA or fixed in Bouin's solution and embedded in paraffin for histological examination.

\section{GPR1 antibody-PGF2 $\alpha$ model}

Twenty-five-day-old immature female mice were injected i.p. with $1 \mathrm{mg} / \mathrm{kg}$ mouse GPR1 antibody and $5 \mathrm{IU}$ of PMSG, followed by the injection of $1 \mathrm{mg} / \mathrm{kg}$ mouse GPR1 antibody and $5 \mathrm{IU}$ of hCG $48 \mathrm{~h}$ after PMSG, another group injected $1 \mathrm{mg} / \mathrm{kg}$ rat IgG as control, $96 \mathrm{~h}$ after
hCG, injected PGF2 $\alpha$ to induce luteolysis, another group injected saline as control. Ovaries and blood samples (collected by removal of eyeball) were taken at $6 \mathrm{~h}$ after PGF2 $\alpha$ and saline injected. Serum was send to Beijing North Institute of Biological Technology to measure hormone level of estradiol, progesterone and testosterone. Ovaries were either snap frozen in RNAiso Plus and stored at $-80^{\circ} \mathrm{C}$ for RNA or fixed in Bouin's solution and embedded in paraffin for histological examination.

\section{RNA analysis by quantitative PCR}

Total RNA from tissues was extracted using RNAiso Plus and subjected to qPCR analysis. RNA samples $(0.5 \mu \mathrm{g})$ were reverse transcribed into cDNA according to the manufacturer's instructions (Toyobo, Osaka, Japan). The PCR mixtures contained 10 $\mu \mathrm{L}$ SYBR Premix Ex Taq II (Toyobo), $1 \mu \mathrm{L}$ of each primer, $1 \mu \mathrm{L}$ cDNA, and $7 \mu \mathrm{L}$ DNasefree water to a final volume of $20 \mu \mathrm{L}$. Cycle conditions were $10 \mathrm{~s}$ at $95^{\circ} \mathrm{C}$, followed by 45 cycles at $95^{\circ} \mathrm{C}$ for $5 \mathrm{~s}$, at $60^{\circ} \mathrm{C}$ for $30 \mathrm{~s}$, and at $72^{\circ} \mathrm{C}$ for $30 \mathrm{~s}$. The reaction was completed with a dissociation step for melting point analysis at $50-95^{\circ} \mathrm{C}$ (in increments of $0.5^{\circ} \mathrm{C}$ for $10 \mathrm{~s}$ each). The primers were designed on the basis of the published sequences of Chemerin (forward, TGTGCAGTGGGCCTTCCA; reverse, CAAAGGTGCCAGCTGAGAAGA), Gpr1 (forward, GGAG CTCAGCATTCATCACA; reverse, GACAGGCTCTTGGTTT CAGC), steroidogenic acute regulatory protein (Star; forward, CTGCTAGACCAGCCCATGGAC; reverse, TGATT TCCTTGACATTTGGGTTCC), cytochrome P450 cholesterol side-chain cleavage (P450scc; forward, CTATGCCATG GGTCGAGAAT; reverse, CAGCACGTTGATGAGGAAGA), 3 $\beta$-hydroxysteroid dehydrogenase ( $H s d 3 b$; forward, AGCA AAAAGATGGCCGAGAA; reverse, GGCACAAGTATGCAA TGTGCC), and $\beta$-actin (forward, GGAAATCGTGCGTGA CATTA; reverse, AGGAAGGAAGGCTGGAAGAG).

The RNA levels were calculated by $2^{-\Delta C T}$ method, where CT was the cycle threshold (Livak \& Schmittgen 2001). The PCR products were confirmed by sequencing. Melting curve analysis for each primer set revealed only one peak for each product, and the sizes of PCR products were confirmed by comparing sizes with a commercial ladder after agarose gel electrophoresis. The results of real-time PCR products were normalized to a stable control, $\beta$-actin, which was used as the reference gene.

\section{Immunohistochemistry}

Ovaries from 25-day-old C57BL/6 mice were dissected after decapitation and then fixed, processed for embedding

Published by Bioscientifica Ltd. 
in paraffin, and sectioned. IHC was carried out on $5 \mu \mathrm{m}$ sections of paraffin-embedded tissue. The primary antibodies used for IHC were mouse GPR1 (clone 043, gift from B A Zabel and E Butcher, Stanford University, Stanford, CA, USA), mouse StAR (ab96637, Abcam), and mouse caspase-3 (Abcam), diluted 1:100 in PBS with $1 \%$ BSA. The secondary antibodies were horseradish peroxidase (HRP)-donkey-anti-rat (Abcam) to GPR1 and HRP-anti-rabbit (Cell Signaling Technology, Beverly, MA, USA) to caspase 3 and StAR, diluted 1:200 in PBS with $1 \%$ BSA. Staining was visualized using a DAB Substrate Kit for peroxidase (Gene Tech, Hyderabad, India), and slides were counterstained with hematoxylin. Control sections were immunostained with a nonspecific IgG to check for nonspecific staining.

\section{Follicle culture}

Twenty-five-day-old immature female mice were injected i.p. with 5 IU of PMSG (ProSpec) to stimulate follicular development. Forty-eight hours after PMSG injection, mice were killed, and both ovaries were removed. A $1 \mathrm{~mL}$ syringe needle was used to remove fat and mesangial tissue around the ovary, and then eye tweezers and needles were used to mechanically isolate follicles under a stereomicroscope. Follicles isolated from the same ovary were added to a single well of a 24-well plate with $1 \mathrm{~mL}$ DMEM F12, cocultured with $100 \mathrm{nM}$ recombinant mouse chemerin (R\&D Systems), $0.01 \mathrm{IU} / \mathrm{mL}$ hCG (Sigma) and $15 \mathrm{nM} \quad\left(\mathrm{IC}_{50}=3 \mathrm{nM}\right)$ phosphoinositide 3-kinase (PI3K) signaling pathway inhibitor wortmannin (Invitrogen). For groups receiving antibody treatment, follicles were precultured for $1-2 \mathrm{~h}$ with $0.5 \mu \mathrm{g} / \mathrm{mL}$ mouse GPR1 antibody (Stanford Brian's laboratory) before drug added. Other groups added $0.5 \mu \mathrm{g} / \mathrm{mL}$ rat IgG (Abcam) as control. Plates were incubated at $37^{\circ} \mathrm{C}, 5 \% \mathrm{CO}_{2}$ ( $\mathrm{Li}$ et al. 2014a), and follicles and media were collected after $6 \mathrm{~h}$. Media were analyzed for hormone levels by the Beijing North Institute of Biological Technology, and follicles were added to RNAiso Plus and stored at $-80^{\circ} \mathrm{C}$ for $\mathrm{qPCR}$ detection of related genes.

\section{Luteal tissue culture}

Twenty-five-day-old immature female mice were injected i.p. with 5 IU of PMSG (ProSpec) to stimulate follicular development, followed by injection of $5 \mathrm{IU}$ of hCG (Sigma) $48 \mathrm{~h}$ after PMSG injection to induce ovulation. Seventy-two hours after hCG injection, mice werekilled, ovaries were removed, fat and mesangial tissue were removed from around the ovary using a $1 \mathrm{~mL}$ syringe needle, and luteal tissue was mechanically separated under a stereomicroscope using eye tweezers and needles. Luteal tissue isolated from the same ovary were added to a single well of a 24-well plate with $1 \mathrm{~mL}$ DMEM F12, cocultured with $100 \mathrm{nM}$ recombinant mouse chemerin (R\&D Systems) and $0.01 \mathrm{IU} / \mathrm{mL}$ hCG (Sigma). For groups receiving antibody treatment, follicles were precultured for $1-2 \mathrm{~h}$ with $0.5 \mu \mathrm{g} / \mathrm{mL}$ mouse GPR1 antibody (Stanford Brian's laboratory) before adding drug. Other groups added $0.5 \mu \mathrm{g} / \mathrm{mL}$ rat IgG (Abcam) as control. Plates were incubated at $37^{\circ} \mathrm{C}, 5 \% \mathrm{CO}_{2}$, and luteal tissue and media were collected after $24 \mathrm{~h}$. Media were analyzed for hormone levels by the Beijing North Biotechnology Research Institute and luteal tissue was placed in RNAiso Plus and stored at $-80^{\circ} \mathrm{C}$ for qPCR detection.

\section{Hormone measurements by RIA}

Progesterone and estradiol levels in conditioned media were measured using commercial iodine [125I] RIA Kits (Beijing North Biotechnology Research Institute). The sensitivity of the progesterone and estradiol RIA assays was $20 \mathrm{ng} / \mathrm{mL}$. The intra-assay error and inter-assay error were $<10$ and $<15 \%$, respectively.

\section{Statistical analysis}

All data are presented as mean \pm s.E.M. and statistical significance was assessed by either one-way ANOVA followed by Fisher's least significant difference test for post hoc comparisons or the Student's t-test (GraphPad Prism). A $P$ value of $<0.05$ was considered to be statistically significant.

\section{Results}

\section{Expression of Chemerin and Gpr1 in mouse ovary during the estrous cycle}

Chemerin and Gpr1 mRNAs were found to be expressed in mouse ovary during the estrous cycle (Fig. 1A and B), suggesting that chemerin and GPR1 play direct or indirect roles in the regulation of follicle and corpus luteum development. IHC staining showed that, at various stages of the estrous cycle, Gpr1 was expressed at high levels in developing follicles at all stages of development and in

Published by Bioscientifica Ltd. 

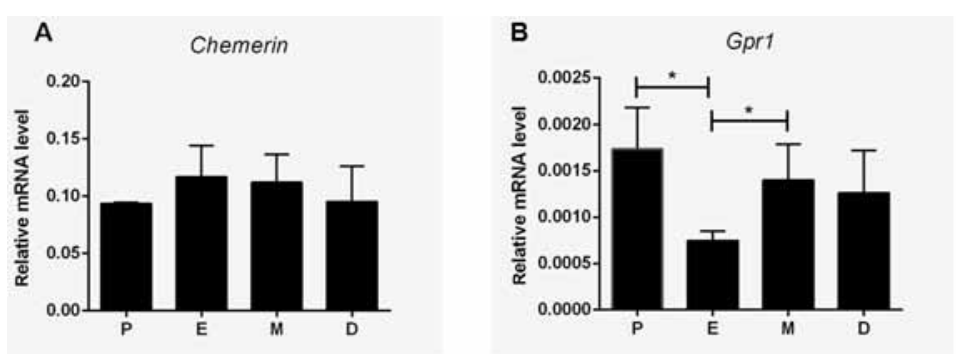

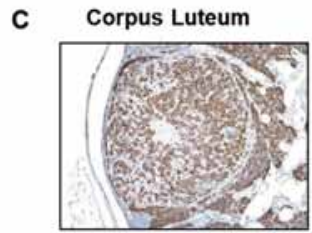

Follicle
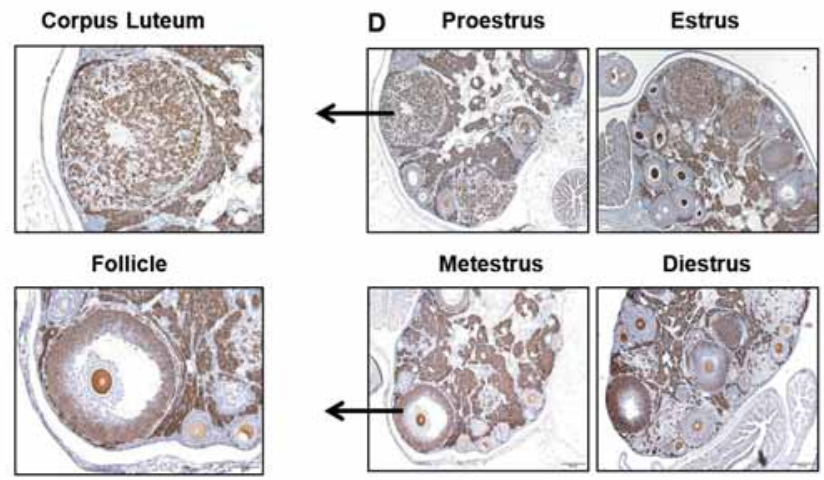

Diestrus

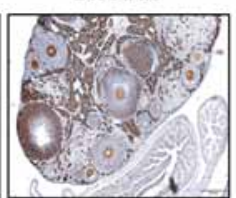

Ctrl

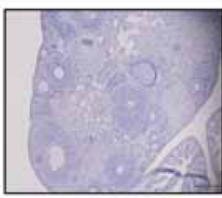

gure

Expression of Chemerin and Gpr1 in mouse ovary during the estrous cycle. (A) Chemerin mRNA expression was measured by qPCR analysis of ovaries from 8- to 12-week-old female mice, $N \geq 3$. (B) Gpr1 mRNA expression was measured by qPCR analysis of ovaries from 8- to 12-week-old female mice, $N \geq 3$; Student's $t$-test, $* P<0.05$ as indicated. (C) Immunolocalization of GPR1 in corpus luteum and follicles. Scale bars $=50 \alpha \mathrm{m}$. (D)

Immunolocalization of GPR1 in mouse ovary during the estrous cycle. Parallel sections are immunostained with nonimmune serum as a control; scale bars $=100 \alpha \mathrm{m}$. the stroma, mainly in thecal cells, granulosa cells, luteal cells, and interstitial cells (Fig. 1C and D). Interestingly, Gpr1 staining in the follicle appears to be mostly in the oocytes, and absent in the granulosal cells of all except the tertiary follicles, which could be studied furthermore. These results indicate that the chemerin/GPR1 signaling pathway plays an important role in follicular development and corpus luteum formation.

\section{In a mouse superovulation model, chemerin can suppress hCG-stimulated progesterone production in follicle and luteal tissue cultures}

Gpr1 is highly expressed in the oocytes, interstitial tissue, granulosa cells, and theca cells, specifically in the corpus luteum of superovulated mouse ovaries. IHC staining showed that, on the second day after PMSG injection, follicles were either mature or in the process of ovulation, and on the third day after hCG injection, the number and size of corpus lutea was at their greatest (Fig. 2).

Antral follicles were isolated under a stereomicroscope. Different drug treatments had different effects on progesterone secretion. After hCG treatment, progesterone levels increased substantially, indicating that hCG could promote the secretion of progesterone. After chemerin cotreatment with hCG, the progesterone level increase was significantly attenuated, indicating that chemerin may suppress progesterone secretion. Interestingly, when a PI3K signaling pathway inhibitor was added, the suppressive effect of chemerin almost disappeared, suggesting that chemerin suppresses progesterone secretion through PI3K signaling. Furthermore, in the presence of both chemerin and hCG, the suppressive effect of chemerin was reduced by GPR1 MAB treatment, indicating that GPR1 is the active receptor acting through the PI3K pathway to mediate chemerin's effect on progesterone secretion (Fig. 3).

Luteal tissue from superovulating ovaries was isolated under a stereomicroscope (Fig. 4A). As observed for follicle culture, different drug treatments had different influences on progesterone secretion. For the pre-IgG control group, after hCG treatment, progesterone levels increased remarkably, whereas with further addition of chemerin, the progesterone increase was significantly inhibited. For the GPR1 antibody treatment group, the pattern was same as that for the control group, except that progesterone levels were higher under all conditions (Fig. 4B). In addition, hCG stimulation resulted in the upregulation of key steroidogenic factors, such as Star, P450scc, and $3 \beta$-Hsd. The suppressive effect of chemerin on hCG-stimulated progesterone production was accompanied by the suppression of hCG-stimulated expression of Star, P450scc, and $3 \beta-H s d$. When anti-GPR1 antibody was added, the suppressive effect disappeared (Fig. 4C, D and E).

From the above results, it can be inferred that chemerin could suppress progesterone secretion through its receptor, GPR1, during ovarian follicle development and in the process of corpus luteum formation.

Published by Bioscientifica Ltd. 
A
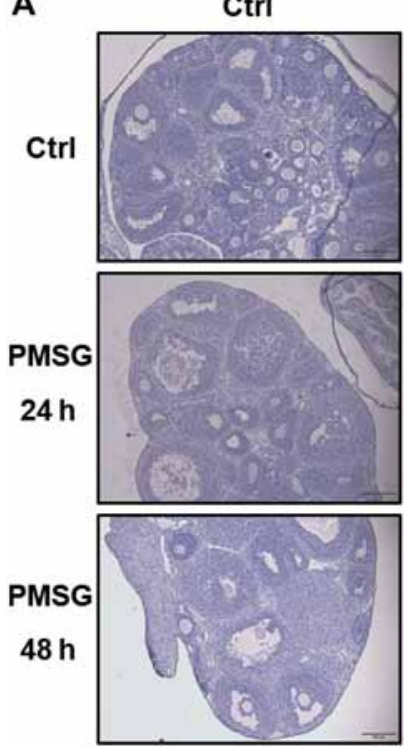
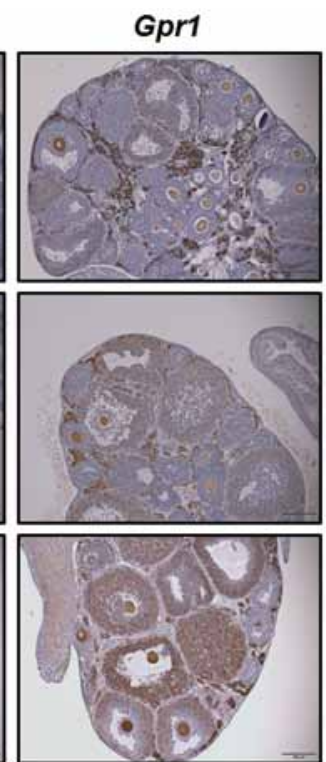

B
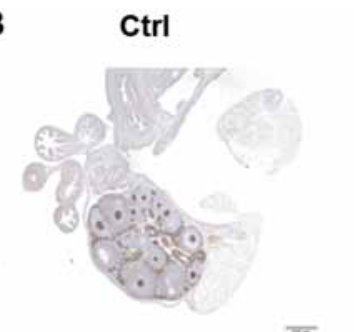

hCG $48 \mathrm{~h}$

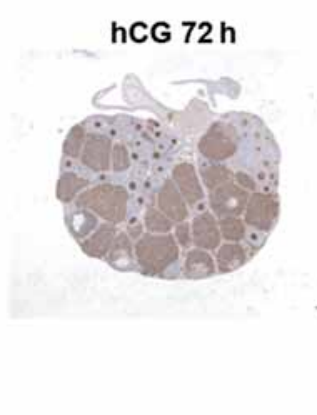

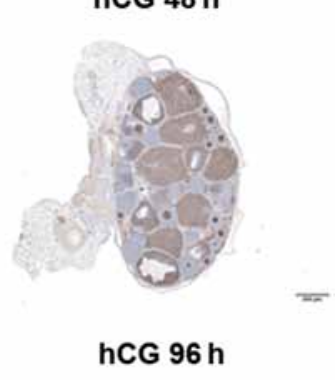

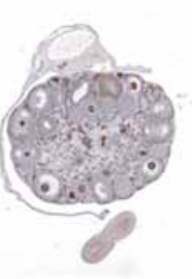

Figure 2

Immunolocalization of Gpr1 in mouse ovary during superovulation. (A) Immunolocalization of GPR1 in mouse ovary after i.p. PMSG; in this phase, follicles develop and mature. Scale bars $=100 \mu \mathrm{m}$. (B) Immunolocalization of GPR1 in mouse ovary after i.p. hCG; in this phase, ovulation occurs, followed by corpus luteum formation and regression. Parallel sections were immunostained with nonimmune serum as a control; scale bars $=1 \mathrm{~mm}$.

\section{In postpartum corpus luteum, PGF2 $\alpha$ could induce luteolysis while GPR1 expression decreases}

The superovulation model is based on the use of immature female mice treated with hormones to artificially induce maturation and ovulation, leading to corpus luteum formation. In order to study the role of chemerin/GPR1 signaling in the development of ovarian follicles and the corpus luteum, we established a natural mature corpus

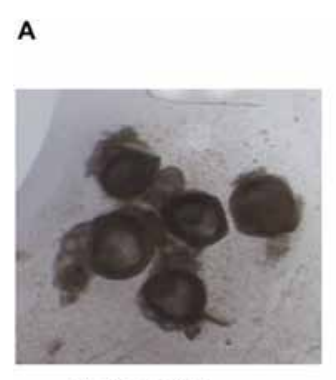

Mouse follicle

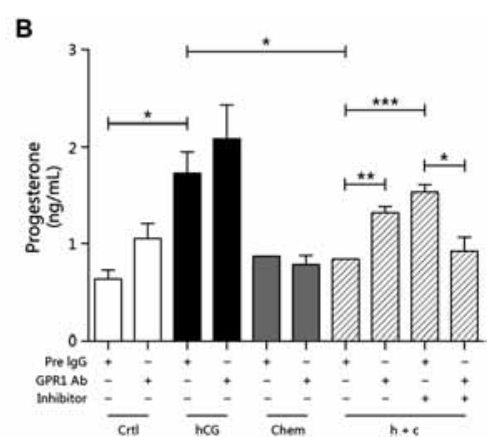

Figure 3

Suppressive effect of chemerin on progesterone in mouse follicles in an in vitro model. (A) Dissected antral follicle. (B) Progesterone levels in cultured follicles with different treatments. Inhibitor, PI3K inhibitor wortmannin; Chem, chemerin; $h+c$, hCG + chemerin. Each experiment was performed at least three times; all data are presented as mean \pm S.E.M.; ${ }^{*} P<0.05, * * P<0.01, * * * P<0.005$ for one-way ANOVA followed by Fisher's least significant difference test. luteum model. On the third to fifth days postpartum, immunohistochemical results showed that Gpr1 was still highly and specifically expressed in the corpus luteum with positive staining for StAR. On the third day after birth in mice, the structure of corpus luteum was still complete and had not been regressed (Fig. 5), so we chose the third day postpartum to establish the PGF2A-induced luteolysis model in mice.

In the PGF2 $\alpha$-induced luteolysis model, first, compared with the control group, serum progesterone levels in the PGF2 $\alpha$ injection group decreased significantly (Fig. 6A), and corpus luteum structure was relatively regressed compared with that in the control group. qPCR showed that Gpr1 mRNA levels in the PGF2 $\alpha$-injected ovary have a declined tendency relative to levels in the control group, but there was no significant difference (Fig. 6B). IHC staining with anti-GPR1 antibody produced a weaker signal in the PGF2 $\alpha$-treated corpus luteum than in the corpus lutea from the control group (Fig. 6C and D), suggesting that the expression of Gpr1 declines during the process of PGF $2 \alpha$-induced luteolysis.

\section{In superovulating corpus luteum, GPR1 antibody suppresses PGF2 $\alpha$-induced luteolysis}

GPR1 antibody was injected into 25-day-old mice undergoing PMSG-hCG-induced superovulation, while

Published by Bioscientifica Ltd 
A

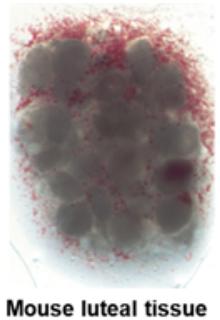

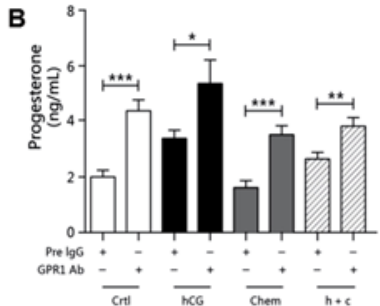

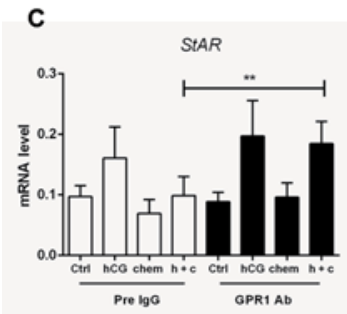

D

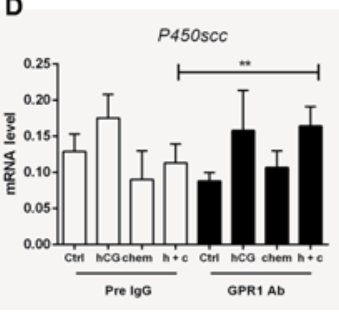

E

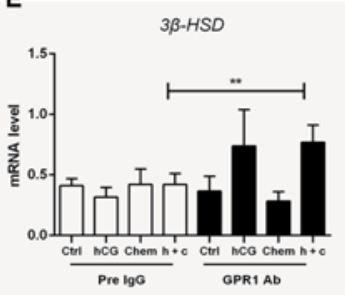

Figure 4

Suppressive effect of chemerin on progesterone in luteal tissue in an in vitro model. (A) Dissected mouse luteal tissue. (B) Progesterone levels in cultured luteal tissue with different treatments. Chem, chemerin; $\mathrm{h}+\mathrm{c}$, hCG + chemerin. Each experiment was performed at least three times. (C) Relative gene expression of Star in cultured luteal tissue. (D) Relative gene expression of $P 450$ scc in cultured luteal tissue. (E) Relative gene expression of $3 \beta-H S D$ in cultured luteal tissue. $\beta$-actin served as the reference gene; $* P<0.05$, $* * P<0.01, * * * P<0.005$ for one-way ANOVA followed by Fisher's least significant difference test; $n \geq 3$, all data are presented as mean \pm s.E.M. pre-immune IgG injection served as a control. On the second day after hCG injection, PGF2 $\alpha$ was administrated to induce luteolysis. The levels of Caspase-3 mRNA in the GPR1 antibody-injected group was significantly reduced compared with levels in the control group after PGF2 $\alpha$ injection (Fig. 7B). Furthermore, immunolocalization of Caspase-3 showed that the number of apoptotic luteal cells was significantly reduced in the GPR1 antibodyinjected group (Fig. 7A).

After GPR1 antibody treatment, serum progesterone levels rose significantly, in accordance with the follicle and luteal tissue culture results. After PGF2 $\alpha$ injection, progesterone levels decreased significantly, but serum progesterone levels were significantly higher in the mice with GPR1 antibody administration than in the pre-IgG control group (Fig. 7C). The trend in serum estradiol levels was roughly the same as that for progesterone (Fig. 7D). These results showed that, after blocking the function of GPR1, PGF2 $\alpha$-induced apoptosis and hormone secretion in the corpus luteum was suppressed, indicating that chemerin signaling is mediated by GPR1 and plays a role in promoting luteolysis.

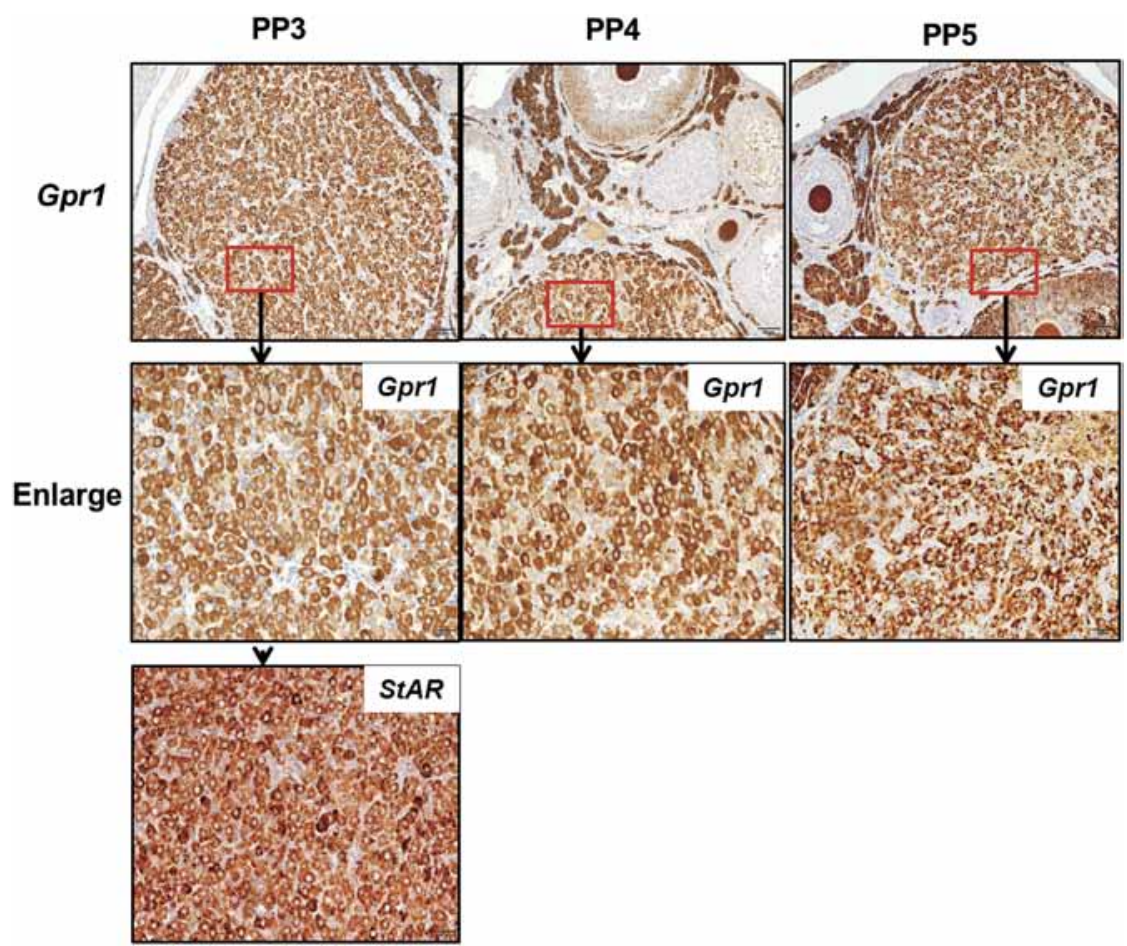

\section{Figure 5}

Immunolocalization of Gpr1 and StAR in postpartum mouse ovary. PP3, third-day postpartum; PP4, fourth-day postpartum; PP5, fifth-day postpartum. Parallel sections were immunostained with nonimmune serum as a control; scale bars $=50 \mu \mathrm{m}$. Enlarged images of corpus luteum are shown in the lower panels. scale bars $=20 \mu \mathrm{m}$. http://joe.endocrinology-journals.org
DOI: 10.1530/JOE-15-0521
(C) 2016 Society for Endocrinology Printed in Great Britain 


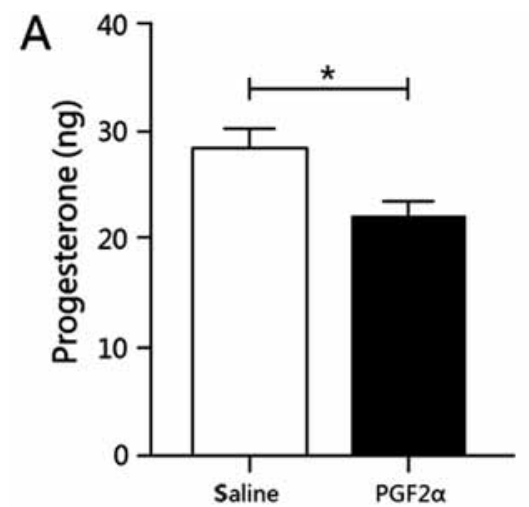

C Saline

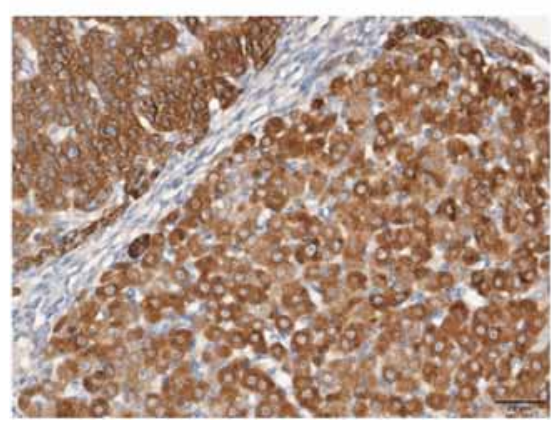

B

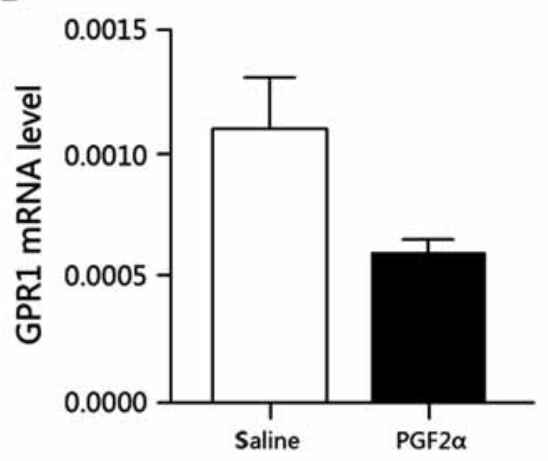

D PGF2 $\alpha$

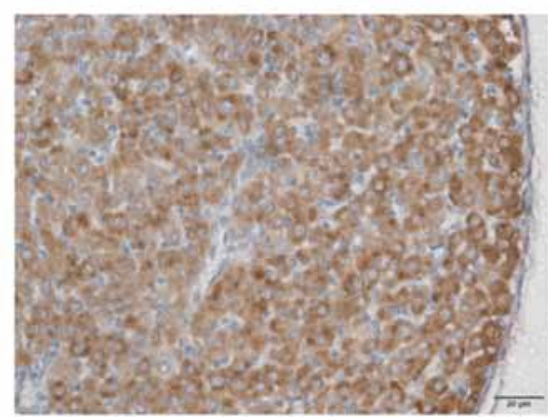

Figure 6

Gpr1 expression decreases in PGF2 $\alpha$-induced postpartum luteolysis. (A) Serum progesterone levels in saline control- and PGF2 $\alpha$-injected mice. (B) Gpr1 mRNA levels in the ovaries of controland PGF2 $\alpha$-injected mice. (C) Immunolocalization of Gpr1 in the saline-injected control group. (D) Immunolocalization of Gpr1 in the PGF2 $\alpha$-injected group. Scale bars $=20 \mu \mathrm{m}$. $\beta$-actin served as the reference gene; $n \geq 3$, all data are presented as mean \pm S.E.M.; ${ }^{*} P<0.05$ for the Student's $t$-test.

\section{Discussion}

Follicular development directly influences the number of ova and ovarian endocrine functions, such as secretion of steroid hormones (estrogen, progesterone, and testosterone) (Su \& Eppig 2002). Theca cells, granulosa cells, and oocytes are the three main ovarian cells. Theca cells secrete androgen; granulosa cells use androgen to synthesize estrogen and can also secrete progesterone independently. The synthetic process is regulated by a series of steroid synthetases, including StAR, P450scc, 3ß-HSD, and 17ß-HSD (Liu \& Hsueh 1986).

Schipper et al. (1993) found that FSH and luteinizing hormone (LH) can increase the levels of progesterone and estrogen in granulosa cells exponentially using in vitro cultured human ovarian granulosa cells. Some cytokines also have an effect on granulosa cells: insulinlike growth factor (IGF) can promote estrogen secretion by granulosa cells (Monniaux \& Pisselet 1992); TNF- $\alpha$ can inhibit FSH stimulation of granulosa cell aromatase activity, and can suppress LH, resulting in a reduction in androgen production (Zolti et al. 1991); interleukin 1 (IL-1) can reduce the ability of granulosa cells to synthesize progesterone, and reduce luteinizing hormone receptor (LHR) in granular cells (Rivier \& Vale 1989). Recent studies have demonstrated that resistin is expressed in pig granulosa cells and that this also increases follicle progesterone and testosterone synthesis and secretion by increasing the expression of CYP11A1, 3 -HSD, CYP17A1, 17 $\beta$-HSD, and CYP19A1 (Sirotkin et al. 2001).

In our study, we found that chemerin and its receptor, Gpr1, were highly expressed in ovaries in multiple stages of the estrous cycle, we infer that chemerin and GPR1 may have regulatory effects on the processes of follicular development and corpus luteum formation. IHC results showed that Gpr1 was localized to follicular granulosa cells, theca cells, and the cumulus oophorus. The staining in the follicle appears to be mostly in the oocytes, and absent in the granulosal cells of all except the tertiary follicles. Based on this interesting finding we have two types of hypotheses, the first is that GPR1 may be involved in oocyte growth and maturation, the second is that the expression of GPR1 on granulosa cell or theca cell may associate with the formation of mature follicle, while we need to do more research to confirm our hypothesis. In vitro follicle culture indicated that chemerin suppresses hCG-induced progesterone secretion by follicles at a concentration of $100 \mathrm{nM}$, whereas when GPR1 antibody was added, the suppressive effect of chemerin weakened, and when a PI3K signaling inhibitor was added, the inhibitory effect of chemerin was abrogated (Fig. 8A). From these results, we speculate that the chemerin/GPR1 
A

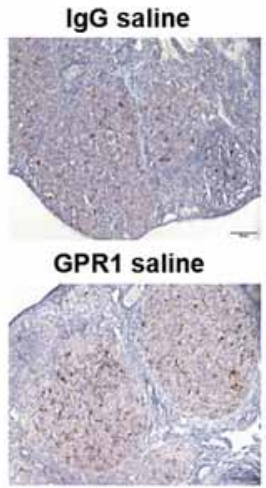

C
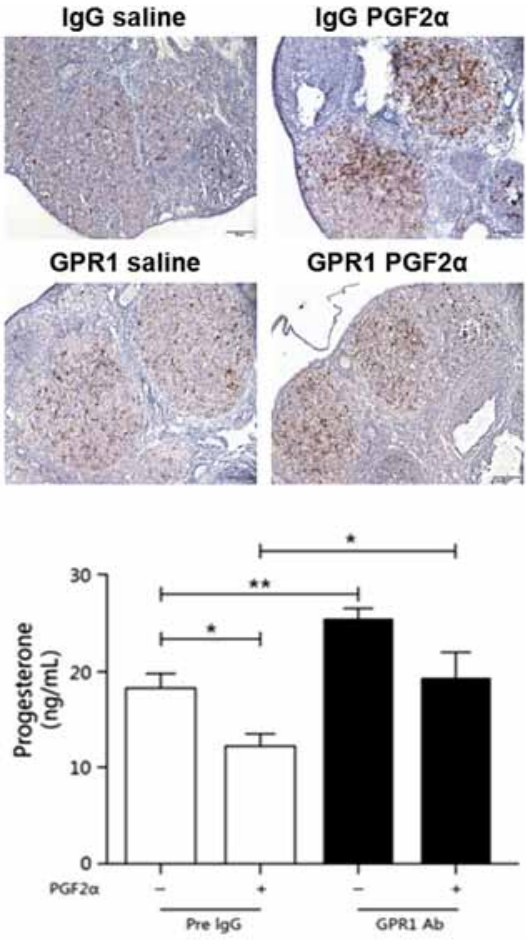

B

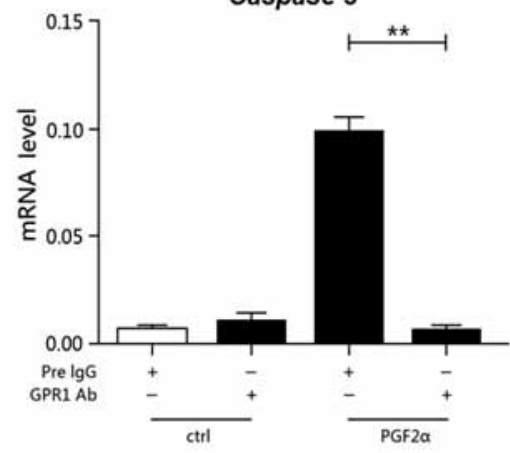

D

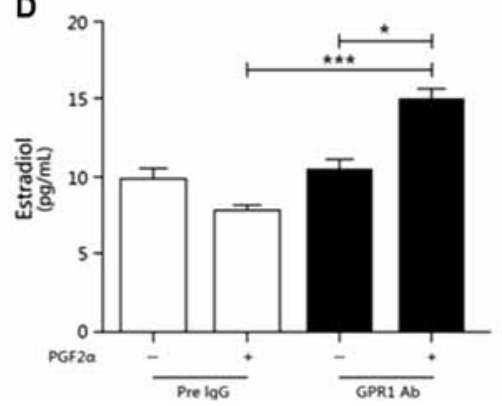

Figure 7

Caspase-3 expression and serum hormone levels in the PGF2 $\alpha$ in vivo model. (A) Immunolocalization of Caspase-3 in GPR1 antibody injection model mouse ovaries; scale bars $=50 \mu \mathrm{m}$. (B) Caspase-3 mRNA levels in GPR1 antibody injection model mouse ovaries. (C) Serum progesterone levels in the GPR1 antibody injection model. (D) Serum estradiol levels in the GPR1 antibody injection model; $n \geq 3, * P<0.05$, $* * P<0.01, * * * P<0.005$ for one-way ANOVA followed by Fisher's least significant difference test. All data are presented as mean \pm S.E.M. and PI3K signaling pathways are involved in processes associated with follicular development, such as progesterone production and secretion.

The corpus luteum is a temporary endocrine organ that plays an important role in the process of female reproductive cycle regulation and maintenance of pregnancy; luteal phase defect (LPD) can cause female infertility or first trimester miscarriage (Wuttke et al. 2001).

The corpus luteum is formed by rupture of follicles after ovulation and is associated with rapid blood vessel growth (Reynolds et al. 2003). Its main physiological function is to secrete steroid hormones, mainly progesterone, but also androgen and estradiol. Androgen stimulates the secretion of estrogen and progesterone, while the most important function of estradiol is to promote the formation of blood vessels in the middle of pregnancy (Skarzynski et al. 2008). Formation of early luteal blood vessels plays a very important role in the development of the corpus luteum. At present, many studies have indicated that vascular endothelial growth factor (VEGF) plays a central role in the formation and evolution of the corpus luteum (Duncan et al. 2008). Adipose cytokines have also been reported in the process of corpus luteum development. Nicklin et al. (2007) found that leptin also had a positive effect on the establishment of the corpus luteum.

In our study, Gpr1 was found to be highly expressed in the corpus luteum, while chemerin was found to suppress hCG-induced progesterone secretion by the corpus luteum at a concentration of $100 \mathrm{nM}$, and the suppression was accompanied by the inhibition of Star and P450scc expression. With the addition of GPR1 antibody, the suppressive effect of chemerin weakened, and the expression of Star and P450scc recovered (Fig. 8A). This means that the chemerin/GPR1 signaling pathway plays an important role in the development of the corpus luteum.

In order to maintain normal reproductive function, without fertilization or pregnancy failure, luteolysis occurs. In rodents, luteolysis has two stages:
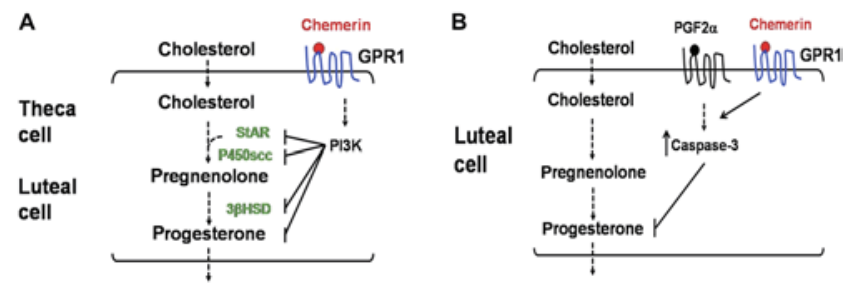

Figure 8

Chemerin/GPR1 signaling suppresses progesterone synthesis and secretion during follicle/corpus luteum development and luteolysis in mice. (A) Chemerin could suppress progesterone synthesis through its receptor GPR1 during follicle and corpus luteum development in mice, the process go through PI3K pathway and effect some key enzymes such as StAR, P450scc, and 3-HSD in the synthesis of progesterone. (B) PGF2 $\alpha$ lead to caspase-3, highly expressed, further induced luteolysis and progesterone level significantly decreased. Chemerin cooperate with this process through its receptor GPR1. 
the first stage is functional degradation, when progesterone levels drop significantly, while the second stage is structural degradation, when there is programed death of luteal cells (Xuejing et al. 2013). These processes are affected by many factors (Stocco et al. 2007), with PGF2 $\alpha$ playing an important role.

By inhibiting cholesterol transport (Pescador et al. 1996), side chain rupture (Murdoch et al. 1996), and the stimulation of progesterone synthesis by gonadotropin (Bjurulf et al. 1998), inhibiting the release of progesterone (Hayashi \& Miyamoto 1999) and reducing the concentration of progesterone in serum and in the corpus luteum, PGF2 $\alpha$ causes corpus luteum dissolution. Damage to luteal cell membranes and the induction of luteal cell apoptosis (Bo et al. 1999) lead to corpus luteum structural degradation, involving in a variety of cytokines and immune functions.

In our PGF2 $\alpha$-induced luteolysis mouse model, expression of Gpr1 and serum progesterone levels decreased, and Caspase-3 expression increased. While the addition of GPR1 antibody elevated serum progesterone levels, expression of Caspase-3 declined significantly, and PGF2 $\alpha$-induced luteolysis was suppressed (Fig. 8B). We conclude that chemerin participates in the process of luteolysis through GPR1.

In conclusion, chemerin/GPR1 signaling was found to play an important role in follicular development, corpus luteum development, and luteolysis and may suppress progesterone secretion and promote PGF $\alpha \alpha$ induced luteolysis. The effect of chemerin and GPR1 on steroidogenesis in the corpus luteum and luteolysis will potentially lead to therapeutic interventions into infertility caused by LPD.

\section{Declaration of interest}

The authors declare that there is no conflict of interest that could be perceived as prejudicing the impartiality of the research reported.

\section{Funding}

This work was supported by the National Major Basic Research Program of China (2013CB945503) to J V Z, Guangdong Grant 2015A020212030 to P G R, Shenzhen Grant (KQCX20140521115045442 to J Z, ZDSYS201504301707152 to L K X, JCYJ20150403105513698 to L R R, and JCYJ20150401150223631 to P G R).

\section{Author contribution statement}

J V Z and Y L Y conceived and designed the experiments; $C \mathrm{H}, \mathrm{B} B \mathrm{~B}$, J C, and $T X X$ performed the experiments; $Y L Y, L F S$, and $L R R$ analyzed the data; L R R, B A Z, and P G R contributed reagents/materials/analysis tools/ housing animals; $Y L Y, J V Z$, and P G R wrote and revised the manuscript.

\section{Acknowledgments}

The authors acknowledge the assistance of Matt Petitt in improving the English grammar, particularly the syntax of the manuscript.

\section{References}

Becker JB, Arnold AP, Berkley KJ, Blaustein JD, Eckel LA, Hampson E, Herman JP, Marts S, Sadee W \& Steiner M 2005 Strategies and methods for research on sex differences in brain and behavior. Endocrinology 146 1650-1673. (doi:10.1210/en.2004-1142)

Bjurulf E, Toffia O, Selstam G \& Olofsson JI 1998 Luteolysis induced by a prostaglandin F2alpha analogue occurs independently of prolactin in the rat. Biology of Reproduction 59 17-21. (doi:10.1095/ biolreprod59.1.17)

Bo RR, Hendry IR, Tilly JL \& Hamernik DL 1999 Accumulation of caspase- 3 messenger ribonucleic acid and induction of caspase activity in the ovine corpus luteum following prostaglandin F2 $\alpha$ treatment in vivo. Biology of Reproduction 60 1087-1092. (doi:10.1095/ biolreprod60.5.1087)

Bondue B, Wittamer V \& Parmentier M 2011 Chemerin and its receptors in leukocyte trafficking, inflammation and metabolism. Cytokine \& Growth Factor Reviews 22 331-338. (doi:10.1016/j.cytogfr.2011.11.004)

Bozaoglu K, Bolton K, McMillan J, Zimmet P, Jowett J, Collier G, Walder K \& Segal D 2007 Chemerin is a novel adipokine associated with obesity and metabolic syndrome. Endocrinology 148 4687-4694. (doi:10.1210/en.2007-0175)

Caminos JE, Nogueiras R, Gaytan F, Pineda R, Gonzalez CR, Barreiro ML Castano JP, Malagon MM, Pinilla L, Toppari J, et al. 2008 Novel expression and direct effects of adiponectin in the rat testis. Endocrinology 149 3390-3402. (doi:10.1210/en.2007-1582)

Devoto L, Fuentes A, Kohen P, Cespedes P, Palomino A, Pommer R, Munoz A \& Strauss JF 3rd 2009 The human corpus luteum: life cycle and function in natural cycles. Fertility and Sterility 92 1067-1079. (doi:10.1016/j.fertnstert.2008.07.1745)

Duan DM, Niu JM, Lei Q, Lin XH \& Chen X 2012 Serum levels of the adipokine Chemerin in preeclampsia. Journal of Perinatal Medicine $\mathbf{4 0}$ 121-127. (doi:10.1515/jpm.2011.127)

Duncan WC, van den Driesche S \& Fraser HM 2008 Inhibition of vascular endothelial growth factor in the primate ovary up-regulates hypoxia-inducible factor-1alpha in the follicle and corpus luteum. Endocrinology 149 3313-3320. (doi:10.1210/en.2007-1649)

Fatima SS, Rehman R, Baig M \& Khan TA 2014 New roles of the multidimensional adipokine: Chemerin. Peptides 62 15-20. (doi:10.1016/j.peptides.2014.09.019)

Garces MF, Sanchez E, Acosta BJ, Angel E, Ruiz AI, Rubio-Romero JA, Dieguez C, Nogueiras R \& Caminos JE 2012 Expression and regulation of Chemerin during rat pregnancy. Placenta 33 373-378. (doi:10.1016/j.placenta.2012.02.007)

Goralski KB, McCarthy TC, Hanniman EA, Zabel BA, Butcher EC, Parlee SD, Muruganandan S \& Sinal CJ 2007 Chemerin, a novel adipokine that regulates adipogenesis and adipocyte metabolism. Journal of Biological Chemistry 282 28175-28188. (doi:10.1074/jbc. M700793200)

Hausman GJ \& Barb CR 2010 Adipose tissue and the reproductive axis: biological aspects. Endocrine Development 19 31-44. (doi:10.1159/000316895)

Hayashi K \& Miyamoto A 1999 Angiotensin II interacts with prostaglandin F2alpha and endothelin-1 as a local luteolytic factor in the bovine corpus luteum in vitro. Biology of Reproduction $\mathbf{6 0}$ 1104-1109. (doi:10.1095/biolreprod60.5.1104)

Li L, Huang C, Zhang X, Wang J, Ma P, Liu Y, Xiao T, Zabel BA \& Zhang JV 2014a Chemerin-derived peptide C-20 suppressed gonadal steroidogenesis. American Journal of Reproductive Immunology $\mathbf{7 1}$ 265-277. (doi:10.1111/aji.12164) 
Li L, Ma P, Huang C, Liu Y, Zhang Y, Gao C, Xiao T, Ren PG, Zabel BA \& Zhang JV 2014b Expression of Chemerin and its receptors in rat testes and its action on testosterone secretion. Journal of Endocrinology 220 155-163. (doi:10.1530/JOE-13-0275)

Liu YX \& Hsueh AJ 1986 Synergism between granulosa and thecainterstitial cells in estrogen biosynthesis by gonadotropin-treated rat ovaries: studies on the two-cell, two-gonadotropin hypothesis using steroid antisera. Biology of Reproduction 35 27-36. (doi:10.1095/ biolreprod35.1.27)

Livak KJ \& Schmittgen TD 2001 Analysis of relative gene expression data using real-time quantitative PCR and the 2(-Delta Delta C(T)) Method. Methods 25 402-408. (doi:10.1006/meth.2001.1262)

Monniaux D \& Pisselet C 1992 Control of proliferation and differentiation of ovine granulosa cells by insulin-like growth factor-I and follicle-stimulating hormone in vitro. Biology of Reproduction 46 109-119. (doi:10.1095/biolreprod46.1.109)

Murdoch WJ, Austin KA \& Hansen TR 1996 Polyubiquitin up-regulation in corpora lutea of prostaglandin. Endocrinology $\mathbf{1 3 7}$ 4526-4529. (doi:10.1210/endo.137.10.8828519)

Nazarko VY, Thevelein JM \& Sibirny AA 2008 G-protein-coupled receptor Gpr1 and G-protein Gpa2 of cAMP-dependent signaling pathway are involved in glucose-induced pexophagy in the yeast Saccharomyces cerevisiae. Cell Biology International 32 502-504. (doi:10.1016/j. cellbi.2007.11.001)

Nicklin LT, Robinson RS, Marsters P, Campbell BK, Mann GE \& Hunter MG 2007 Leptin in the bovine corpus luteum: receptor expression and effects on progesterone production. Molecular Reproduction \& Development 74 724-729. (doi:10.1002/mrd.20671)

Pate JL, Johnson-Larson CJ \& Ottobre JS 2012 Life or death decisions in the corpus luteum. Reproduction in Domestic Animals $\mathbf{4 7}$ (Supplement 4) 297-303. (doi:10.1111/j.1439-0531.2012.02089.x)

Peng L, Yu Y, Liu J, Li S, He H, Cheng N \& Ye RD 2015 The Chemerin receptor CMKLR1 is a functional receptor for amyloid-beta peptide. Journal of Alzheimer's Disease 43 227-242. (doi:10.3233/JAD-141227)

Pescador N, Soumano K, Stocco DM, Price CA \& Murphy BD 1996 Steroidogenic acute regulatory protein in bovine corpora lutea. Biology of Reproduction 55 485-491. (doi:10.1095/ biolreprod55.2.485)

Reverchon M, Cornuau M, Rame C, Guerif F, Royere D \& Dupont J 2012 Chemerin inhibits IGF-1-induced progesterone and estradiol secretion in human granulosa cells. Human Reproduction 27 1790-1800. (doi:10.1093/humrep/des089)

Reynolds LP, Grazul-Bilska AT \& Redmer DA 2003 Angiogenesis in the corpus luteum. Reproductive Biology \& Endocrinology 1 1-8.

Rivier C \& Vale W 1989 In the rat, interleukin-1 alpha acts at the level of the brain and the gonads to interfere with gonadotropin and sex steroid secretion. Endocrinology 124 2105-2109. (doi:10.1210/endo124-5-2105)

Rourke JL, Muruganandan S, Dranse HJ, McMullen NM \& Sinal CJ 2014 Gpr1 is an active Chemerin receptor influencing glucose homeostasis in obese mice. Journal of Endocrinology 222 201-215. (doi:10.1530/ JOE-14-0069)

Schipper I, Fauser BCJM, Gaver EBOV, Zarutskie PW \& Dahl KD 1993 Endocrinology: development of a human granulosa cell culture model with follicle stimulating hormone responsiveness. Human Reproduction 8 1380-1386.

Sirotkin AV, Makarevich AV, Corkins MR, Kotwica J \& Bulla J 2001 The transfection-induced overexpression of IGF-binding protein- 4 affects the secretory activity of porcine ovarian granulosa cells and their response to hormones and IGF-I. Journal of Molecular Endocrinology 26 241-248. (doi:10.1677/jme.0.0260241)

Skarzynski DJ, Ferreira-Dias G \& Okuda K 2008 Regulation of luteal function and corpus luteum regression in cows: hormonal control, immune mechanisms and intercellular communication. Reproduction in Domestic Animals 43 57-65. (doi:10.1111/j.14390531.2008.01143.x)

Stocco C, Telleria C \& Gibori G 2007 The molecular control of corpus luteum formation, function, and regression. Endocrine Reviews $\mathbf{2 8}$ 117-149. (doi:10.1210/er.2006-0022)

Su YQ \& Eppig JJ 2002 Evidence that multifunctional calcium/ calmodulin-dependent protein kinase II (CaM KII) participates in the meiotic maturation of mouse oocytes. Molecular Reproduction \& Development 61 560-569. (doi:10.1002/mrd.10034)

Tan BK, Chen J, Farhatullah S, Adya R, Kaur J, Heutling D, Lewandowski KC, O’Hare JP, Lehnert H \& Randeva HS 2009 Insulin and metformin regulate circulating and adipose tissue Chemerin. Diabetes 58 1971-1977. (doi:10.2337/db08-1528)

Tena-Sempere M, Pinilla L, Gonzalez LC, Dieguez C, Casanueva FF \& Aguilar E 1999 Leptin inhibits testosterone secretion from adult rat testis in vitro. Journal of Endocrinology 161 211-218. (doi:10.1677/ joe.0.1610211)

Wang Q, Leader A \& Tsang BK 2013 Inhibitory roles of prohibitin and Chemerin in FSH-induced rat granulosa cell steroidogenesis. Endocrinology 154 956-967. (doi:10.1210/en.2012-1836)

Wittamer V, Franssen JD, Vulcano M, Mirjolet JF, Le Poul E, Migeotte I, Brezillon S, Tyldesley R, Blanpain C, Detheux M, et al. 2003 Specific recruitment of antigen-presenting cells by Chemerin, a novel processed ligand from human inflammatory fluids. Journal of Experimental Medicine 198 977-985. (doi:10.1084/jem.20030382)

Wuttke W, Pitzel L, Seidlová-Wuttke D \& Hinney B 2001 LH pulses and the corpus luteum: the luteal phase deficiency LPD. Vitamins \& Hormones 63 131-158. (doi:10.1016/S0083-6729(01)63005-X)

Xuejing Z, Jianhua L, Jiali L, Haoshu L, Kemian G \& Sheng C 2013 Prostaglandin F2 $\alpha$ upregulates Slit/Robo expression in mouse corpus luteum during luteolysis. Journal of Endocrinology 218 299-310. (doi:10.1530/JOE-13-0088)

Zabel BA, Zuniga L, Ohyama T, Allen SJ, Cichy J, Handel TM \& Butcher EC 2006 Chemoattractants, extracellular proteases, and the integrated host defense response. Experimental Hematology $\mathbf{3 4}$ 1021-1032. (doi:10.1016/j.exphem.2006.05.003)

Zabel BA, Nakae S, Zuniga L, Kim JY, Ohyama T, Alt C, Pan J, Suto H, Soler D, Allen SJ, et al. 2008 Mast cell-expressed orphan receptor CCRL2 binds Chemerin and is required for optimal induction of IgE-mediated passive cutaneous anaphylaxis. Journal of Experimental Medicine 205 2207-2220. (doi:10.1084/jem.20080300)

Zolti M, Ben-Rafael Z, Meirom R, Shemesh M, Bider D, Mashiach S \& Apte RN 1991 Cytokine involvement in oocyte and early embryo. Fertility \& Sterility 56 265-272.

Received in final form 1 April 2016

Accepted 4 May 2016

Accepted Preprint published online 5 May 2016 http://joe.endocrinology-journals.org

DOI: $10.1530 / J O E-15-0521$
(C) 2016 Society for Endocrinology Printed in Great Britain
Published by Bioscientifica Ltd. 